\title{
The Lower Infusion Rate of Glucose to Maintain Ketogenesis within Normal Level during Surgery
}

\author{
Jun Hirokawa, Sayuri Kadowaki, Masanori Tsukamoto, Takashi Hitosugi, Takeshi Yokoyama \\ Department of Dental Anesthesiology, Faculty of Dental Science, Kyushu University, Fukuoka, Japan \\ Email: hj8823@dent.kyushu-u.ac.jp, s.koyama@dent.kyushu-u.ac.jp, tsukamoto@dent.kyushu-u.ac.jp, \\ hitosugi.takashi.724@m.kyushu-u.ac.jp, yokoyama@dent.kyushu-u.ac.jp
}

How to cite this paper: Hirokawa, J., Kadowaki, S., Tsukamoto, M., Hitosugi, T. and Yokoyama, T. (2017) The Lower Infusion Rate of Glucose to Maintain Ketogenesis within Normal Level during Surgery. Open Journal of Anesthesiology, 7, 264-274. https://doi.org/10.4236/ojanes.2017.78027

Received: July 21, 2017

Accepted: August 27, 2017

Published: August 30, 2017

Copyright $\odot 2017$ by authors and Scientific Research Publishing Inc. This work is licensed under the Creative Commons Attribution International License (CC BY 4.0).

http://creativecommons.org/licenses/by/4.0/ Open Access

\begin{abstract}
Background: Intraoperative low-dose glucose infusions suppress ketogenesis and attenuate postoperative insulin resistance (IR). However, the appropriate rate for intraoperative glucose infusion remains unclear, although a postoperative infusion of $0.08 \mathrm{~g} / \mathrm{kg} / \mathrm{h}$ effectively suppressed ketogenesis at the next morning. Therefore, we investigated the effects of an intraoperative rate of $0.08 \mathrm{~g} / \mathrm{kg} / \mathrm{h}$ on ketogenesis and postoperative IR. Methods: The present study included 15 patients who were undergoing maxillofacial surgery. The patients received glucose-free Ringer's solution and a continuous glucose infusion $(0.08 \mathrm{~g} / \mathrm{kg} / \mathrm{h})$ during the surgery. Blood samples were collected to evaluate the concentrations of noradrenaline, cortisol, glucose, insulin, ketone bodies, and free fatty acid before anesthesia induction (T1), at $1 \mathrm{~h}$ after induction (T2), at $3 \mathrm{~h}$ after induction (T3), and at the end of surgery (T4). The glucose clamp test was performed on the days before and after surgery using the STG-55 ${ }^{\mathrm{TM}}$ device. IR was quantified using the mean glucose infusion rate (M-value). Results: All 15 patients exhibited intraoperative blood glucose concentrations of $90-130 \mathrm{mg} / \mathrm{dL}$. There was a non-significant trend towards higher plasma concentrations of total ketone bodies at T3 $(p=0.058)$. The plasma concentrations of acetoacetic acid at T3 and T4 were significantly higher than that at T1 ( $p=0.0217$ and $p=0.0306$, respectively). All patients exhibited lower M-values after surgery (mean reduction: $48.0 \% \pm 17.9 \%$ ). Conclusion: Continuous intraoperative glucose at $0.08 \mathrm{~g} / \mathrm{kg} / \mathrm{h}$ helped maintain blood glucose concentrations, although it may suppress the ketogenesis to increase during surgery.
\end{abstract}

\section{Keywords}

Glucose Administration, Insulin Resistance, Metabolism, Ketogenesis, General Anesthesia 


\section{Introduction}

The ideal management of glucose concentrations during the perioperative period remains unclear, and hyperglycemia may worsen surgical outcomes because it results in reperfusion injury and suppresses the immune system [1]-[8]. Moreover, postoperative insulin sensitivity is reduced in proportion to the magnitude of the surgical invasion [9]. The state of reduced insulin sensitivity is called insulin resistance, and postoperative insulin resistance may contribute to hyperglycemia [10]. Therefore, glucose administration has been avoided during surgery [11] [12] [13]. However, patients are typically required to fast for several hours before surgery to avoid vomiting during the induction of anesthesia, and patients may experience nutritional stress during long surgeries. In this context, glucose is necessary for activities of the brain, red blood cells, and kidney medulla, and it is stored as glycogen in the muscle and liver. However, the total amount of stored glycogen is insufficient to support the basal energy expenditure for one day, and gluconeogenesis may be increased in fasting patients [14].

We have previously reported that a $1.5 \%$ glucose infusion (average administration rate: $0.15 \mathrm{~g} / \mathrm{kg} / \mathrm{h}$ ) during surgery can suppress ketogenesis and attenuate postoperative insulin resistance without causing hyperglycemia [15]. We also found that postoperative glucose infusion $(0.08 \mathrm{~g} / \mathrm{kg} / \mathrm{h})$ effectively suppressed ketogenesis at the next morning [15]. However, there is insufficient evidence regarding the appropriate postoperative glucose dose and administration rate. In addition, overfeeding can result in nutritional stress, such as protein breakdown, edema, and glucotoxicity [16] [17]. Furthermore, refeeding using a high glucose load may result in an abnormal sodium balance, abnormal fluid balance, and even death among patients who have been fasting for a prolonged time [18] [19]. Moreover, rapid variability in blood glucose concentrations may enhance apoptosis in the endothelial cells of the human umbilical vein [20]. Based on our findings regarding the effects of postoperative glucose infusion at a rate of 0.08 $\mathrm{g} / \mathrm{kg} / \mathrm{h}$, we hypothesized that this rate might suppress intraoperative ketogenesis and attenuate postoperative insulin resistance when the surgical stress is controlled also during surgery. Therefore, the present study prospectively evaluated the serum concentrations of ketone bodies and postoperative insulin resistance among patients who received intraoperative glucose administration at 0.08 $\mathrm{g} / \mathrm{kg} / \mathrm{h}$ during maxillofacial surgery.

\section{Methods}

This prospective study was performed using methods that were very similar to our previous study [15]. After obtaining approval from the Ethics Committee of Kyushu University Hospital, we obtained written informed consent from patients who were undergoing elective maxillofacial surgery and had an American Society of Anesthesiologists physical status of I-II. We excluded patients with diabetes millitus and/or obesity (a body mass index [BMI] of $>25 \mathrm{~kg} / \mathrm{m}^{2}$ ). 


\subsection{Anesthetic Management}

Patients received no premedication and no oral intake was permitted after $9 \mathrm{PM}$ on the night before surgery. Routine monitoring was performed when the patient arrived at the operating room, which included pulse oximetry, electrocardiography, noninvasive blood pressure measurements, and capnography. After taking the blood sample for the baseline measurements, general anesthesia was induced using $4 \mu \mathrm{g} / \mathrm{kg}$ of fentanyl and $0.1 \mathrm{mg} / \mathrm{kg}$ of midazolam, and maintained using sevoflurane ( $1 \%-2 \%)$. Intubation was facilitated using $0.1 \mathrm{mg} / \mathrm{kg}$ of vecuronium or $0.6 \mathrm{mg} / \mathrm{kg}$ of rocuronium. Continuous remifentanil administration and intermittent fentanyl administration were performed to ensure analgesia.

After intubation, the patients were connected to the ventilator, which used the following primary respiratory conditions: frequency of $10 / \mathrm{min}$, inspiratory: expiratory ratio of $1: 2$, volume of $8 \mathrm{~mL} / \mathrm{kg}$, and no positive end-expiratory pressure. During the operation, the settings were adjusted to maintain a $\mathrm{P}_{\mathrm{a}} \mathrm{CO}_{2}$ of 35 - $44 \mathrm{mmHg}$ in the blood gas testing.

\subsection{Glucose Administration}

During the surgery, all patients received acetated Ringer's solution without glucose, as well as a continuous glucose infusion at $0.08 \mathrm{~g} / \mathrm{kg} / \mathrm{h}$ via a side tube. The solutions were infused at a rate of $20 \mathrm{~mL} / \mathrm{kg} / \mathrm{h}$ for $1 \mathrm{~h}$ after the induction of anesthesia, and then the infusion rate was reduced to $5 \mathrm{~mL} / \mathrm{kg} / \mathrm{h}$. No other fluids (e.g., plasma or colloids) were administered, with the exception of $100 \mathrm{~mL}$ of saline for the administration of antibiotics.

\subsection{Continuous Blood Glucose Monitoring}

After the induction of anesthesia, an intravenous catheter (Insyte ${ }^{\mathrm{TM}}, 20$ gauge, 1.16 in; Becton Dickinson Infusion Therapy System, Sandy, UT) was inserted into the antebrachial vein and connected to the STG-55 ${ }^{\mathrm{TM}}$ system (Nikkiso Company, Tokyo, Japan) for continuous blood glucose monitoring during the operation. A 22-gauge catheter was inserted into the radial arterial for intermittent blood sampling, and glucose concentrations and blood gas levels were evaluated every $2 \mathrm{~h}$.

\subsection{Evaluation of Insulin Resistance}

Insulin resistance was evaluated using the glucose clamp technique (hyperinsulinemic normoglycemic clamp technique), as this method is considered the golden standard for measuring insulin sensitivity [21] [22]. Insulin was infused at $1.25 \mathrm{mIU} / \mathrm{kg} / \mathrm{min}$, and the plasma insulin concentration was maintained at approximately $100 \mu \mathrm{IU} / \mathrm{mL}$. The plasma glucose concentration was held at 90 $\mathrm{mg} / \mathrm{dL}$ using a variable-rate glucose infusion, based on the negative feedback principle, after the glucose infusion rate (GIR, $\mathrm{mg} / \mathrm{kg} / \mathrm{min}$ ) had reached a steady state. Insulin resistance was quantified using the mean GIR during the steady state period. This technique was performed using data from the STG- $55^{\mathrm{TM}}$, based 
on our methods with the STG- $22^{\mathrm{TM}}$ from our previous study [15], as the STG- $55^{\mathrm{TM}}$ is the next generation after the STG- $22^{\mathrm{TM}}$ model and has equivalent ability to measure insulin sensitivity [23].

After fasting overnight, the procedure was started at $9 \mathrm{AM}$ on the day before surgery. A 20-gauge intravenous catheter was inserted into the peripheral vein and connected to the STG-55 ${ }^{\mathrm{TM}}$ for blood glucose monitoring. Another catheter was inserted into the peripheral vein of the opposite arm for infusing the glucose and insulin solutions. The test was repeated at $9 \mathrm{AM}$ on the morning after the surgery.

\subsection{Measuring Ketone Bodies, Free Fatty Acid, Plasma Glucose, and Insulin Concentrations}

Blood samples were collected before the induction of anesthesia (T1), at $1 \mathrm{~h}$ after the induction of anesthesia (T2), at $3 \mathrm{~h}$ after the induction of anesthesia (T3), and at the end of surgery (T4) to determine the serum concentrations of noradrenaline, cortisol, plasma glucose, insulin, ketone bodies, and free fatty acid (FFA).

\subsection{Statistical Analysis}

All data were presented as mean \pm standard deviation. The blood sample parameters and hemodynamic data were compared using analysis of variance. When a significant difference was noted, the post-hoc Tukey-Kramer test for time was performed for multiple comparisons. A p-value of $<0.05$ was considered statistically significant, and all analyses were performed using JMP Pro software (version 11; SAS Institute Inc., Raleigh, NC, USA).

\section{Results}

This study included 15 patients (13 women and 2 men). All patients underwent osteotomy of the maxilla and/or the mandible, because of a jaw deformity, between February 2013 and August 2015. No patients received insulin or other fluid infusions during the surgery, with the exception of scheduled autologous blood transfusions. The patient characteristics and anesthetic procedures are listed in Table 1, and the hemodynamic and bispectral index data are listed in Table 2.

The serum concentrations of noradrenaline and cortisol were significantly lower at T2 - T4, compared to at T1 $(p<0.01)$. The blood glucose concentrations exhibited minor variations between $90 \mathrm{mg} / \mathrm{dL}$ and $130 \mathrm{mg} / \mathrm{dL}$ during the surgery. No hyperglycemia was observed in all patients (Figure 1), although the glucose concentrations at $\mathrm{T} 3$ and $\mathrm{T} 4$ were significantly higher than those at $\mathrm{T} 1$ $(p<0.001$ and $p=0.0052$, respectively). The plasma insulin concentrations at $\mathrm{T} 2$ were significantly lower than those at $\mathrm{T} 1(p=0.0023)$, the concentrations at T3 were significantly higher than those at T1 $(p=0.0109)$, and the concentrations at $\mathrm{T} 4$ were similar to the $\mathrm{T} 1$ values (Table 3 ). We observed no significant 
Table 1. Patient characteristics and intra-operative variables.

\begin{tabular}{cc}
\hline & $(\mathbf{n}=15)$ \\
Male/Female & $2 / 13$ \\
Age (year) & $29.6 \pm 6.71$ \\
Height $(\mathrm{cm})$ & $161.6 \pm 7.37$ \\
Weight $(\mathrm{kg})$ & $56.8 \pm 9.27$ \\
BMI $\left(\mathrm{kg} / \mathrm{m}^{2}\right)$ & $21.7 \pm 2.60$ \\
Fasting time $(\mathrm{min})$ & 675 \\
Anesthesia time $(\mathrm{min})$ & $433 \pm 81.8$ \\
Operation time $(\mathrm{min})$ & $304 \pm 77.3$ \\
Fentanyl $(\mu / \mathrm{kg})$ & $6.9 \pm 2.4$ \\
Remifentanil $(\mu \mathrm{kg} / \mathrm{kg} / \mathrm{hr})$ & $110.7 \pm 49.2$ \\
Infusion $(\mathrm{ml} / \mathrm{kg} / \mathrm{hr})$ & $8.43 \pm 2.30$ \\
Urine output $(\mathrm{ml} / \mathrm{kg} / \mathrm{hr})$ & $1.66 \pm 1.01$ \\
Blood loss $(\mathrm{ml} / \mathrm{kg} / \mathrm{hr})$ & $1.54 \pm 0.77$ \\
Glucose dose $(\mathrm{g} / \mathrm{kg} / \mathrm{hr})$ & 0.08 \\
&
\end{tabular}

Values are given as mean \pm standard deviation. BMI: body mass index.

Table 2. Hemodynamic status and bispectral index values of the patients.

\begin{tabular}{ccccc}
\hline & T1 & T2 & T3 & T4 \\
\hline HR (bpm) & $73.3 \pm 8.65$ & $65.1 \pm 11.2$ & $60.4 \pm 7.4$ & $71.9 \pm 12.9$ \\
SBP (mmHg) & $112.7 \pm 10.6$ & $90.0 \pm 13.8$ & $86.4 \pm 13.6$ & $90.6 \pm 14.2$ \\
DBP (mmHg) & $66.3 \pm 7.8$ & $45.3 \pm 7.4$ & $42.9 \pm 9.3$ & $45.1 \pm 10.9$ \\
BIS values & $97.9 \pm 0.9$ & $47.8 \pm 7.3$ & $47.8 \pm 7.3$ & $54.8 \pm 7.7$ \\
\hline
\end{tabular}

Values are given as mean \pm standard deviation. T1: anesthetic induction; T2: $1 \mathrm{~h}$ after anesthetic induction; T3: $3 \mathrm{~h}$ after anesthetic induction; T4: at the end of surgery; HR: heart rate; SBP: systolic blood pressure; DBP: diastolic blood pressure; BIS: bispectral index.

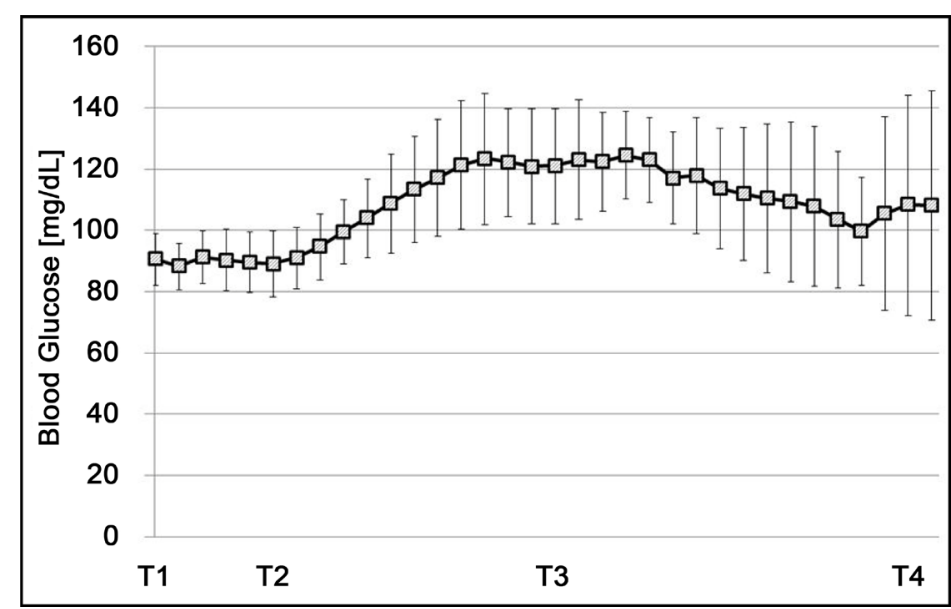

T1: anesthetic induction; T2: $1 \mathrm{~h}$ after anesthetic induction; T3: $3 \mathrm{~h}$ after anesthetic induction; T4: at the end of surgery.

Figure 1. Continuous blood glucose monitoring. 
Table 3. Alternations in the levels of noradrenaline, cortisol, plasma glucose, insulin, ketone bodies, and free fatty acid (FFA).

\begin{tabular}{ccccc}
\hline & $\begin{array}{c}\text { T1 } \\
\text { (baseline) }\end{array}$ & T2 & T3 & T4 \\
\hline Noradrenaline $(\mathrm{pg} / \mathrm{mL})$ & $452.1 \pm 169.0$ & $243.7 \pm 120.3^{*}$ & $253.3 \pm 205.7^{*}$ & $282.1 \pm 163.0^{*}$ \\
Cortisol $(\mu \mathrm{g} / \mathrm{mL})$ & $16.8 \pm 5.6$ & $7.8 \pm 3.0^{* *}$ & $3.2 \pm 1.5^{* *}$ & $1.3 \pm 0.6^{* *}$ \\
Blood glucose $(\mathrm{mg} / \mathrm{dL})$ & $85.1 \pm 5.9$ & $91.8 \pm 6.0$ & $128.4 \pm 17.6^{* *}$ & $107.3 \pm 31.1^{* *}$ \\
Insulin $(\mu \mathrm{IU} / \mathrm{mL})$ & $4.92 \pm 1.57$ & $2.04 \pm 1.22$ & $7.47 \pm 3.47$ & $4.24 \pm 3.64$ \\
Total ketone body $(\mu \mathrm{mol} / \mathrm{L})$ & $113.2 \pm 86.4$ & $112.1 \pm 142.0$ & $179.9 \pm 112.0$ & $110.1 \pm 103.0$ \\
Acetoacetic acid $(\mu \mathrm{mol} / \mathrm{L})$ & $20.6 \pm 15.9$ & $29.5 \pm 20.2$ & $39.7 \pm 23.3^{*}$ & $38.8 \pm 31.5^{*}$ \\
3-hydroxybutyric acid $(\mu \mathrm{mol} / \mathrm{L})$ & $92.6 \pm 70.8$ & $82.6 \pm 52.3$ & $140.2 \pm 72.4$ & $71.3 \pm 72.4$ \\
FFA $(\mu \mathrm{Eq} / \mathrm{L})$ & $640.1 \pm 282.8$ & $677.9 \pm 292.6$ & $578.4 \pm 377.7$ & $447.1 \pm 252.9$ \\
\hline
\end{tabular}

Values are given as mean \pm standard deviation. ${ }^{*} p<0.05,{ }^{* *} p<0.01$ vs. T1. T1: anesthetic induction; T2: 1 $\mathrm{h}$ after anesthetic induction; T3: $3 \mathrm{~h}$ after anesthetic induction; T4: at the end of surgery.

differences in total ketone bodies during surgery. The plasma concentrations of acetoacetic acid at T3 and T4 were significantly higher than those at T1 ( $p=$ 0.0217 and $p=0.0306$, respectively), although there were no significantly differences in the plasma concentrations of 3-hydroxybutyric acid, and no acetone was detected at any measurement (Table 3). The serum FFA concentrations were within the normal limits at all measurements, and we did not observe any significant changes during the surgery (Table 3). Furthermore, no significant changes were observed in the plasma concentrations of noradrenaline and cortisol (Table 3).

In all cases, the glucose infusion rate decreased after surgery. The preoperative glucose infusion rate of $6.62 \pm 1.65 \mathrm{mg} / \mathrm{kg} / \mathrm{min}$ decreased significantly to $3.31 \pm$ $0.98 \mathrm{mg} / \mathrm{kg} / \mathrm{min}(p<0.001)$, which corresponded to a $48.0 \% \pm 17.9 \%$ reduction.

\section{Discussion}

Intraoperative glucose administration is necessary for achieving perioperative metabolic homeostasis, and may contribute to better surgical outcomes [15] [24]. However, there is insufficient information regarding the appropriate intraoperative glucose dose and infusion rate, and especially regarding the lower limits of these values. We also found that postoperative glucose infusion $(0.08$ $\mathrm{g} / \mathrm{kg} / \mathrm{h}$ ) effectively suppressed ketogenesis at the next morning. Therefore, the present study aimed to evaluate the effects of intraoperative continuous glucose administration at $0.08 \mathrm{~g} / \mathrm{kg} / \mathrm{h}$ on blood glucose concentrations, ketogenesis, and postoperative insulin resistance.

Surgical stress affects glucose concentrations and glucose metabolism [25]. In this context, catecholamine and cortisol are secreted in response to various stresses, such as surgical invasion and pain [26]. However, we found that the intraoperative serum concentrations of noradrenaline and cortisol were significantly lower than the baseline concentrations.

Although our previous study revealed that Ringer's solution with $1.5 \%$ glucose 
increased the mean blood glucose concentrations from approximately 100 $\mathrm{mg} / \mathrm{dL}$ to $150 \mathrm{mg} / \mathrm{dL}$ at the induction of anesthesia, because of the rapid infusion rate $(20 \mathrm{~mL} / \mathrm{kg} / \mathrm{h})$ [11], no intraoperative hyperglycemia was detected in the present study. In this context, Risso et al. have reported that fluctuating glucose concentrations exert more negative effects on vein endothelial cells, compared to stably high glucose concentrations [20]. However, a sharp increase in the glucose concentrations was not detected in the present study, which was maintained at $90-130 \mathrm{mg} / \mathrm{dL}$ during the surgery. Similar to the changes in blood glucose concentrations, the insulin concentrations were increased at T3 and subsequently returned to near baseline values at the end of the surgery.

In our previous study, overnight fasting and glucose-free fluid therapy induces ketogenesis [15] [27]. However, intraoperative low-dose glucose (approximately $43 \%$ of basal energy expenditure) effectively suppressed ketogenesis during orthopedic surgery [27]. Furthermore, intraoperative glucose administration (0.15 $\mathrm{g} / \mathrm{kg} / \mathrm{h}$ ) effectively suppressed serum ketone body concentrations during maxillofacial surgery [15]. Those results suggest that, during periods with no dietary or infused glucose, the necessary glucose is supplied from fat by gluconeogenesis. Serum acetoacetic acid concentrations at T3 and T4 were higher than those at T1. However, there were not significant differences in serum concentration of total ketone bodies during surgery. Therefore, we compared the present study's patients (G2 group) with patients from our previous study who had only received Ringer's solution without glucose (R group) or who had received Ringer's solution with $1.5 \%$ glucose (G1 group). Based on this comparison, there is a tendency that the serum ketone bodies concentrations were lower in G2 group than those of $\mathrm{R}$ group, although the trend was not statistically significant. On the other hand, the concentrations in G2 group were significantly lower than those in $\mathrm{R}$ group at T4 (Figure 2). Therefore, these results may suggest that continuous glucose infusions at a rate of $0.08 \mathrm{~g} / \mathrm{kg} / \mathrm{h}$ are the lower limit for suppressing ketogenesis during surgery.

In the present study, the glucose clamp technique was used for quantifying insulin sensitivity before and after surgery. The homeostasis model assessment (HOMA) index is another inexpensive and simply method for quantifying insulin sensitivity [28] [29] [30], however, the HOMA method provides a crude and potentially inaccurate measure of postoperative insulin resistance [22] [31]. In contrast, the glucose clamp technique uses the glucose infusion rate as the indicator of insulin sensitivity, and its value decreased after surgery for all patients in the present study. Furthermore, in our previous study, postoperative insulin resistance in G1 group was effectively attenuated to a level that was comparable to that in the R group. Moreover, G2 group from the present study exhibited a non-significant trend towards a lower reduction rate compared to $\mathrm{R}$ group ( $p=$ 0.197 ), and a trend towards a higher reduction rate compared to G1 group ( $p=$ 0.44 ) (Figure 3). These results suggest that intraoperative glucose infusion at a rate of $0.08 \mathrm{~g} / \mathrm{kg} / \mathrm{h}$ may be insufficient for attenuating postoperative insulin resistance. 


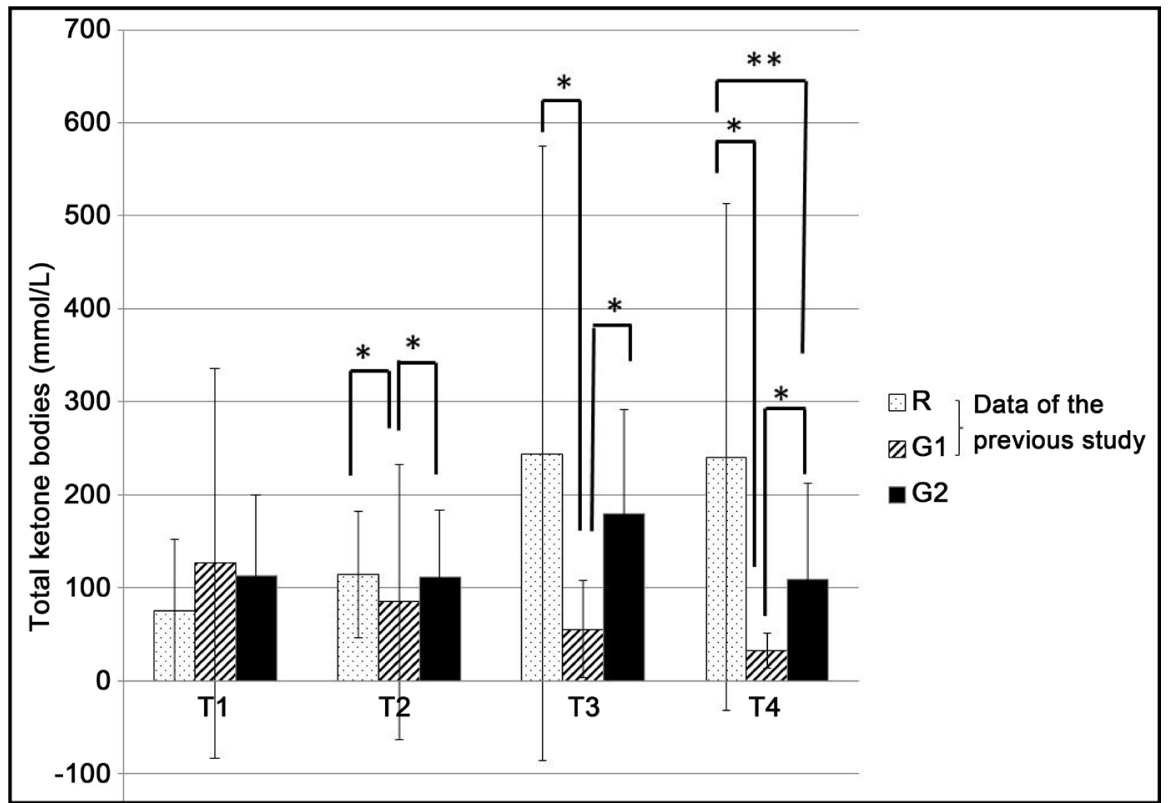

In the $G_{2}$ group, there is a trend towards increasing plasma concentrations of total ketone bodies at T3, although this trend was not statistically significant. ${ }^{\star} p<0.05$ between the groups using the Mann-Whitney $U$ test. T1: anesthetic induction; T2: $1 \mathrm{~h}$ after anesthetic induction; T3: $3 \mathrm{~h}$ after anesthetic induction; T4: at the end of surgery; G2: patients from the present study (glucose infusion at $0.08 \mathrm{~g} / \mathrm{kg} / \mathrm{h}$ ); G1: patients from our previous study (Ref. 23) who received Ringer's solution with $1.5 \%$ glucose; R: patients from our previous study (Ref. 23) who only received glucose-free Ringer's solution.

Figure 2. Changes in total levels of ketone bodies.

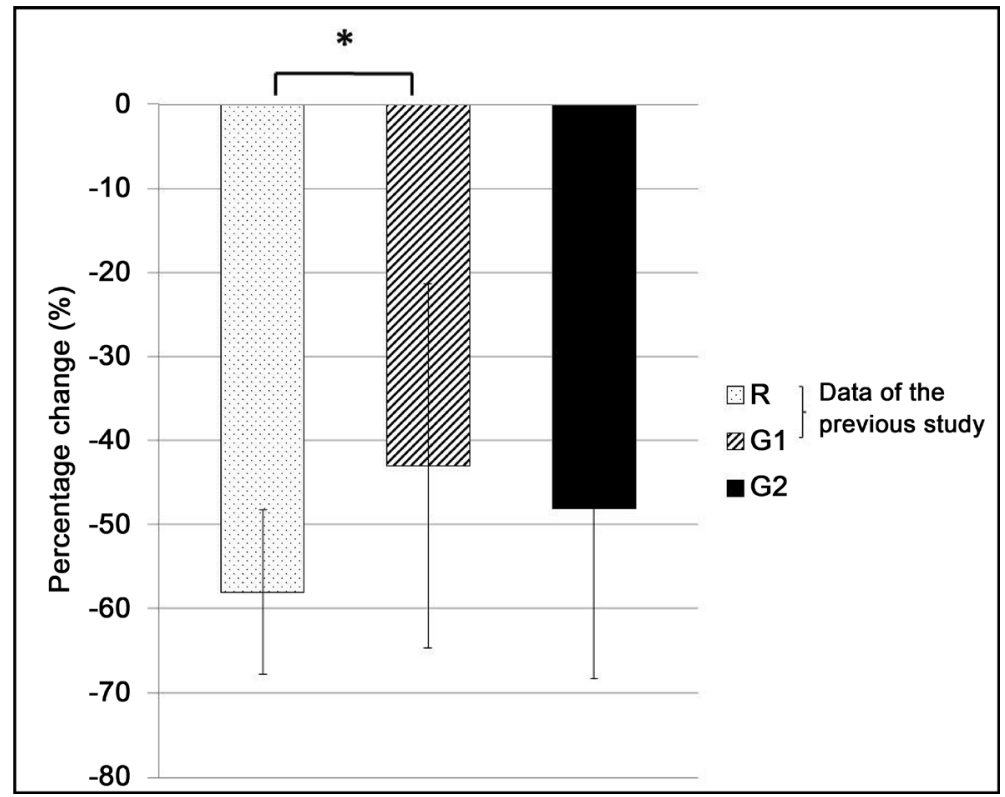

The postoperative reduction in insulin sensitivity (\%) was calculated for all patients (post-operative $\mathrm{M}$-value/pre-operative $\mathrm{M}$-value). There were no significant differences in the reduction rates of the $\mathrm{G}_{2}$ and other groups. ${ }^{*} p<0.05$ using the Mann-Whitney $U$ test. G2: patients from the present study (glucose infusion at $0.08 \mathrm{~g} / \mathrm{kg} / \mathrm{h}$ ); G1: patients from our previous study (Ref. 15) who received Ringer's solution with $1.5 \%$ glucose; R: patients from our previous study (Ref. 15) who only received glucose-free Ringer's solution.

Figure 3. Relative changes in insulin sensitivity. 
The present study has several limitations. First, the same protocol as our previous study was used (except the intraoperative infusion rate of glucose) [15], although, we did not perform randomization or use a control group, and there is some possibility of selection bias. Second, a small sample of patients who were undergoing maxillofacial surgery was evaluated, which is also associated with a risk of selection bias. Therefore, larger prospective studies are needed to confirm whether our findings can be extrapolated to other patient populations and other surgical procedures.

\section{Conclusion}

The present study revealed that continuous intraoperative glucose administration $(0.08 \mathrm{~g} / \mathrm{kg} / \mathrm{h})$ did not rapidly alter the patients' blood glucose concentrations. Moreover, serum ketone bodies concentration was maintained within normal range. We think that the rate $(0.08 \mathrm{~g} / \mathrm{kg} / \mathrm{h})$ may be the lower limit for suppressing intraoperative ketogenesis.

\section{Acknowledgements}

We would like to thank J. Kishimoto (department of research and development of next generation medicine, Kyushu University, Japan) for his advice on statistical analysis of our research data.

\section{Conflicts of Interest}

Financial support for this study was provided by Nikkiso Co. Ltd. (Tokyo, Japan). The funding organization played no part in the study's design, performance, writing the manuscript, or in the decision to publish the results. The authors have no other conflicts of interest.

\section{References}

[1] Pulsinelli, W.A., Levy, D.E., Sigsbee, B., Scherer, P. and Plum, F. (1983) Increased Damage after Ischemic Stroke in Patients with Hyperglycemia with or without Established Diabetes Mellitus. American Journal of Medicine, 74, 540-544. https://doi.org/10.1016/0002-9343(83)91007-0

[2] Berger, L. and Hakim, A.M. (1986) The Association of Hyperglycemia with Cerebral Edema in Stroke. Stroke, 17, 865-871. https://doi.org/10.1161/01.STR.17.5.865

[3] Chopp, M., Welch, K.M.A., Tidwell, C.D. and Helpern, J.A. (1998) Global Cerebral Ischemia and Intracellular $\mathrm{pH}$ during Hyperglycemia and Hypoglycemia in Cats. Stroke, 19, 1383-1387. https://doi.org/10.1161/01.STR.19.11.1383

[4] Lanier, W.L., Stangland, K.J., Scheithauer, B.W., Milde, J.H. and Michenfelder, J.D. (1987) The Effects of Dextrose Infusion and Head Position on Neurologic Outcome after Complete Cerebral Ischemia in Primates: Examination of a Model. Anesthesiology, 66, 39-48. https://doi.org/10.1097/00000542-198701000-00008

[5] Nakakimura, K., Fleischer, J.E., Drummond, J.C., Scheller, M.S., Zornow, M.H., Grafe, M.R. and Shapiro, H.M. (1990) Glucose Administration before Cardiac Arrest Worsens Neurologic Outcome in Cats. Anesthesiology, 72, 1005-1011. https://doi.org/10.1097/00000542-199006000-00010 
[6] Bagdade, J.D., Root, R.K. and Bulger, R.J. (1974) Impaired Leukocyte Function in Patients with Poorly Controlled Diabetes. Diabetes, 23, 9-15. https://doi.org/10.2337/diab.23.1.9

[7] Marhoffer, W., Stein, M., Maeser, E. and Federlin, K. (1992) Impairment of Polymorphonuclear Leukocyte Function and Metabolic Control of Diabetes. Diabetes Care, 15, 256-260. https://doi.org/10.2337/diacare.15.2.256

[8] McManus, L.M., Bloodworth, R.C., Prihoda, T.J., Blodgett, J.L. and Pinckard, R.N. (2001) Agonist-Dependent Failure of Neutrophil Function in Diabetes Correlates with Extent of Hypoglycemia. Journal of Leukocyte Biology, 70, 395-404.

[9] Thorell, A., Efendic, S., Gutniak, M., Häggmark, T. and Ljungqvist, O. (1993) Development of Postoperative Insulin Resistance Is Associated with the Magnitude of Operation. European Journal of Surgery, 159, 593-599.

[10] Nygren, J., Thorell, A., Efendic, S., Nair, S. and Ljungqvist, O. (1997) Site of Insulin Resistance after Surgery: The Contribution of Hypocaloric Nutrition and Bed Rest. Clinical Science, 93, 137-146. https://doi.org/10.1042/cs0930137

[11] Sieber, F., Smith, D.S., Kupferberg, J., Crosby, L., Uzzell, B., Buzby, G., March, K. and Nann, L. (1986) Effects of Intraoperative Glucose on Protein Catabolism and Plasma Glucose Levels in Patients with Supratentorial Tumors. Anesthesiology, 64, 453-459. https://doi.org/10.1097/00000542-198604000-00007

[12] Sieber, F.E., Smith, D.S., Traystman, R.J. and Wollman, H. (1987) Glucose: A Reevaluation of Its Intraoperative Use. Anesthesiology, 67, 72-81. https://doi.org/10.1097/00000542-198707000-00013

[13] Weissman, C. (1990) The Metabolic Response to Stress: An Overview and Update. Anesthesiology, 73, 308-327. https://doi.org/10.1097/00000542-199008000-00020

[14] Rothman, D.L., Magnusson, I., Katz, L.D., Shulman, R.G. and Shulman, G.I. (1991) Quantitation of Hepatic Glycogenolysis and Gluconeogenesis in Fasting Humans with 13C NMR. Science, 254, 573-576. https://doi.org/10.1126/science.1948033

[15] Fujino, H., Itoda, S., Esaki, K., Tsukamoto, M., Sako, S., Matsuo, K., Sakamoto, E., Suwa, K. and Yokoyama, T. (2014) Intra-Operative Administration of Low-Dose IV Glucose Attenuates Post-Operative Insulin Resistance. Asia Pacific Journal of Clinical Nutrition, 23, 400-407.

[16] Terashima, H., Tadano, S. and Okohchi, N. (2009) Theoretical Approach for Estimating Exogenous Energy Provision in the Critical Illness Including Surgical Stress: Breakaway from Existing Calculation Methods for Energy Needs. The Journal of the Japanese Society for Parenteral and Enteral Nutrition, 24, 1027-1043. (In Japanese)

[17] Klein, C.J., Stanek, G.S. and Wiles, C.E. (1998) Overfeeding Macronutrients to Critically Ill Adults: Metabolic Complications. Journal of the American Dietetic Association, 98, 795-806.

[18] Mahanna, H.M., Moledina, J. and Travis, J. (2008) Refeeding Syndrome: What It Is, and How to Prevent and Treat It. BMJ, 336, 1495-1498. https://doi.org/10.1136/bmj.a301

[19] Crook, M.A., Hally, V. and Panteli, J.V. (2001) The Importance of the Refeeding Syndrome. Nutrition, 17, 632-637.

[20] Risso, A., Mercuri, F., Quagliaro, L., Damante, G. and Ceriello, A. (2001) Intermittent High Glucose Enhances Apoptosis in Human Umbilical Vein Endothelial Cells in Culture. American Journal of Physiology-Endocrinology and Metabolism, 281, 924-930.

[21] DeFronzo, R.A., Tobin, J.D. and Andres, R. (1979) Glucose Clamp Technique: A 
Method for Quantifying Insulin Secretion and Resistance. American Journal of Physiology, 237, 214-223.

[22] Fujino, H., Itoda, S., Sako, S., Matsuo, K., Sakamoto, E. and Yokoyama, T. (2013) Reliability of HOMA-IR for Evaluation of Insulin Resistance during Perioperative Period. Masui, 62, 140-146. (In Japanese)

[23] Tsukamoto, Y., Kinoshita, Y., Kitagawa, H., Munekage, M., Munekage, E., Takezaki, Y., Yatabe, T., Yamashita, K., Yamazaki, R., Okabayashi, T., Tarumi, M., Kobayashi, M., Mishita, S. and Hanazaki, K. (2013) Evaluation of a Novel Artificial Pancreas: Closed Loop Glycemic Control System with Continuous Blood Glucose Monitoring. Artificial Organs, 37, 67-73. https://doi.org/10.1111/aor.12068

[24] Sato, H., Carvalho, G., Sato, T., Lettermann, R., Matsukawa, T. and Schricker, T. (2010) The Association of Preoperative Glycemic Control, Intraoperative Insulin Sensitivity, and Outcomes after Cardiac Surgery. The Journal of Clinical Endocrinology \& Metabolism, 95, 4338-4344. https://doi.org/10.1210/jc.2010-0135

[25] Dungan, K.M., Braithwaite, S.S. and Preiser, J.C. (2009) Stress Hyperglycemia. The Lancet, 373, 1798-1807.

[26] Axelrod, J. and Reisine, T.D. (1984) Stress Hormones: Their Interaction and Regulation. Science, 224, 452-459. https://doi.org/10.1126/science.6143403

[27] Yokoyama, T., Suwa, K., Yamasaki, F., Yokoyama, R., Yamashita, K. and Selldén, E. (2008) Intraoperative Infusion of Acetated Ringer Solution Containing Glucose and Ionized Magnesium Reduces Ketogenesis and Maintains Serum Magnesium. Asia Pacific Journal of Clinical Nutrition, 17, 525-529.

[28] Matthews, D.R., Hosker, J.P., Rudenski, A.S., Naylor, B.A., Treacher, D.F. and Turner, R.C. (1985) Homeostasis Model Assessment: Insulin Resistance and $\beta$-Cell Function from Fasting Plasma Glucose and Insulin Concentrations in Man. Diabetologia, 28, 412-419. https://doi.org/10.1126/science.6143403

[29] Kurtoğlu, S., Hatipoğlu, N., Mazıcıoğlu, M., Kendirici, M., Keskin, M. and Kondolot, M. (2010) Insulin Resistance in Obese Children and Adolescents: HOMA-IR Cut-Off Levels in the Prepubertal and Pubertal Periods. Journal of Clinical Research in Pediatric Endocrinology, 2, 100-106. https://doi.org/10.4274/jcrpe.v2i3.100

[30] Ferreira, A.P., Oliveira, C.E.R. and França, N.M. (2007) Metabolic Syndrome and Risk Factors for Cardiovascular Disease in Obese Children: The Relationship with Insulin Resistance (HOMA-IR). Jornal de Pediatria, 83, 21-26. https://doi.org/10.2223/JPED.1562

[31] Baban, B., Thorell, A., Nygren, J., Bratt, A. and Ljungqvist, O. (2015) Determination of Insulin Resistance in Surgery: The Choice of Method Is Crucial. Clinical Nutrition, 34, 123-128. 
Submit or recommend next manuscript to SCIRP and we will provide best service for you:

Accepting pre-submission inquiries through Email, Facebook, LinkedIn, Twitter, etc. A wide selection of journals (inclusive of 9 subjects, more than 200 journals)

Providing 24-hour high-quality service

User-friendly online submission system

Fair and swift peer-review system

Efficient typesetting and proofreading procedure

Display of the result of downloads and visits, as well as the number of cited articles Maximum dissemination of your research work

Submit your manuscript at: http://papersubmission.scirp.org/

Or contact ojanes@scirp.org 